\title{
Experimental investigation on influence of microcapsules with PCM on propylene glycol rheological properties
}

\author{
Krzysztof Dutkowski ${ }^{1}$, and Jacek Jan Fiuk ${ }^{1, *}$ \\ ${ }^{1}$ Koszalin University of Technology, Faculty of Mechanical Engineering, Raclawicka 15-17, 75-620 Koszalin, Poland
}

\begin{abstract}
This paper details an experimental study that was performed to investigate rheological properties of microencapsulated phase change slurry - mPCM (Micronal ${ }^{\mathbb{B}}$ DS 5039 X and ERGOLID EKO ${ }^{\circledR}$ - an aqueous solution of propylene glycol). Seven samples of $\mathrm{mPCM}$ slurry were prepared with different mass ratio of the Micronal ${ }^{\circledR}$ to the ERGOLID EKO ${ }^{\circledR}: 30: 70,40: 60,50: 50,60: 40,70: 30,80: 20$ and 90:10. The apparent viscosity-shear rate curves were obtained for spindle speed from 0.01 to $100 \mathrm{rpm}$ (shear rate 0.0132 to $132.00 \mathrm{~s}^{-1}$ respectively). The steady state measurement of viscosity was carried out when the slurry reached constant temperatures, namely: 10.0; 15.0, 17.5, 20.0, 22.5, 25.0, 27.5, 30.0, 40.0 and 50.0 ${ }^{\circ} \mathrm{C}$. The apparent viscosity of slurries increases with the $\mathrm{MPCM}$ concentration in dispersion rises. Only the sample of $30 \%$ Micronal $^{\mathbb{R}}$ may be considered as a Newtonian fluid within the test range. Increasing the shear rate ultimately causes apparent viscosity to decrease down to the Newtonian plateau, where it seems to be constant. The variation of the viscosity as a function of temperature and microcapsules concentration was accurately represented by a modified Vogel-Tamman-Fulcher equation at a mean absolute error (MAE) of $10.76 \%$
\end{abstract}

\section{Introduction}

Technological advancements have made mass production of capsules with a diameter of the order of micrometers available today. Hence, flow is possible for a whole dispersion of base fluid and microcapsules filled with phase-changing material. Intensive research has been undertaken to determine the thermal properties and flow characteristics of microencapsulated Phase Change Material Slurries (mPCM slurry), which are classified as Latent Functional Thermal Fluid (LFTF)[1]. LTFT is a two-phase working fluid used in heat exchange systems and is characterized by a greater heat transfer capacity (by latent heat in the phase transition temperature range) compared to conventional single-phase fluids.

MPCM slurries offer many advantages and can be used either as thermal storage materials or heat transfer fluids due to: 1) their high storage capacity during phase change; 2) the possibility of using the same medium either to transport or to store energy, as these slurries are pumpable (thus reducing heat transfer losses); 3) heat transfer at an approximately constant temperature; 4) a high heat transfer rate due to the elevated ratio surface/volume; 5) a lower pumping power, as a consequence of the reduction in mass flow rate due to the higher heat capacity; 6) a better heat exchange than conventional heat transfer fluids, due to the decrease in fluid temperature as a consequence of the higher heat capacity. Furthermore, these novel fluids have a more advantageous thermal energy storage density than conventional systems of sensible heat storage in water, and can compete with macroencapsulated PCM tanks. Moreover, the response time may be shorter using these PCM emulsions or mPCM slurries as a storage material than with macro- encapsulated PCM. The tanks will be simpler as there is no need to macroencapsulate, thus conventional tanks can be used [2].

Viscosity plays a significant role in determining the pressure drop and characteristics of fluid flow described by Reynolds and Grashoff number (higher viscosity leads to the lower turbulence of the slurry, so the heat transfer coefficient may be lowered).

\section{Previous study on mPCM slurry viscosity}

Zhang and Zao [3] experimentally investigated the thermal and rheological properties of a series of prepared mPCM slurries fabricated by dispersing microencapsulated PCM into water with an appropriate amount of surfactant. The mass ratio of $\mathrm{mPCM}$ to water and surfactant was 10:90:1, 25:75:1, 35:65:1, respectively. The $\mathrm{mPCM}$ slurry can be considered as Newtonian fluid when the shear rate is higher than $200 \mathrm{~s}^{-1}$ and the PCM microcapsules' mass fraction lower than 35 wt. \%. The viscosity was higher for larger particle slurries.

Delgado et al. [2] experimentally investigated the microencapsulated PCM slurry with three different PCM mass fractions $(14,20$ and $30 \%)$. The studied $\mathrm{mPCM}$ slurry consisted of microcapsules of paraffin coated by a

Corresponding author: jacek.fiuk@tu.koszalin.pl 
polymer and dispersed in water through detergents. These PCM microcapsules had a diameter range from 1 to $20 \mu \mathrm{m}$. The viscosity - shear rate curves using a control stress rheometer were obtained through a shear sweep from 0.001 to $1000 \mathrm{~s}^{-1}$ and at a constant temperature $\left(\mathrm{T}=27^{\circ} \mathrm{C}\right)$. The equation that best predicts the shape of the flow curve for the three mPCM slurries is the non-Newtonian model, namely the Carreau model.

Allouche et al. [4] investigated the $45 \% \mathrm{w} / \mathrm{w}$ aqueous dispersion of RT15 paraffin microcapsules supplied by CIBA chemicals (UK) while a rheological rotational rheometer (UM/MC 100 PHYSICA) was used. Experiments were performed applying constant shear rates from 10 to $500 \mathrm{~s}^{-1}$. Tests were repeated in a temperature range of $7-20^{\circ} \mathrm{C}$. The rheological study revealed a non-Newtonian fluid behaviour of the PCM for different temperature settings.

Kong et al. [5] used mPCM slurries produced by Thies Technology Inc. as heat transfer fluids. The phase change material (PCM) used in the study was butyl stearate. Each microcapsule was made by encapsulating the PCM using polyurea as a shell material, which made up about $35 \%$ of the total volume of each microcapsule. The $\mathrm{mPCM}$ particle size range used in the experiments was between 5 and $10 \mu \mathrm{m}$ in diameter. The apparent viscosity of $\mathrm{mPCM}$ slurries was measured using a coaxial rotating drum viscometer from Brookfield Engineering Laboratories Inc. Microencapsulated PCM slurries with $2.1,5.9,8.3$ and 10.9 wt. \%, respectively, were tested in a temperature range of $5-35^{\circ} \mathrm{C}$. The viscosity was measured at three different rotational speeds of 50,60 and $100 \mathrm{rpm}$. The experimental results showed that the viscosity of mPCM slurry is independent of the shear rate and behaves as a Newtonian fluid.

In a paper by Wang et al. [6] experimental research on the natural convective heat transfer with microencapsulated phase change material suspensions is described. The microencapsulated PCM slurry was formulated with PCM powder with $\mathrm{N}$-hexadecane as the core material and a diameter range of $10 \div 40 \mu \mathrm{m}$. The water-propanol mixture was the base fluid along with the addition of dispersants. The viscosity of $10 \div 30 \mathrm{wt}$. $\% \mathrm{mPCM}$ suspensions was measured with the TADHR-2 rheometer at a room temperature of $20^{\circ} \mathrm{C}$ and shear rate of up to $100 \mathrm{~s}^{-1}$. The 10 wt. $\%$ and 20 wt. $\% \mathrm{mPCM}$ slurry behave as Newtonian fluids while the 30 wt. \% mPCM slurry shows the shear thinning non-Newtonian characteristic.

$\mathrm{Fu}$ et al. [7] conducted experiments on thermophysical properties of n-tetradecane\&polystyrene-silica composite nanoencapsulated phase change material slurry. The mean particle size of Tet@PS-SiO2 mPCM was $151.3 \mathrm{~nm}$. The $\mathrm{mPCM}$ water slurry contained 5\% PCM and 15 wt. \% amount of antifreeze. The viscosity of the slurry was investigated by a Brookfield DV-II + Pro rotation viscometer with $\mathrm{S} 61$ rotor type at $100 \mathrm{rpm}$ in a temperature range from 5 to $25^{\circ} \mathrm{C}$. It was found that the viscosities of all slurries were slightly higher than that of the base fluid.

Generally, the mPCM slurry is considered as a Newtonian fluid when the mass fraction of $\mathrm{mPCM}$ is up to $30 \%[4-6,8,9]$ or when the shear rate is large enough [3]. After adding additives such as surfactant agents, the mPCM slurry stopped behaving as a non-Newtonian fluid and started behaving as a Newtonian fluid [10,11]. The viscosities of slurries rose with the increase of the mass fraction of microcapsules up to several dozen times [5-8,12-15].

The purpose of this study is to investigate the rheological properties of mPCM slurry. In this paper, an mPCM slurry made of a new product, the Micronal ${ }^{\circledR}$ DS $5039 \mathrm{X}$ and ERGOLID EKO ${ }^{\circledR}$ (an aqueous solution of propylene glycol) - as a base fluid, with seven different mass fractions was obtained. The study examines the effect of Micronal ${ }^{\circledR}$ DS 5039 X mass fraction on slurry viscosity along with the effect of temperature increase $\left(10-50^{\circ} \mathrm{C}\right)$ on slurry viscosity. Detailed steady state condition characteristics and a predictive model for this property were obtained.

\section{Experimental setup and procedure}

\subsection{Slurry properties}

Micronal ${ }^{\circledR}$ DS $5039 \mathrm{X}(\mathrm{BASF})$ is an aqueous dispersion of microencapsulated paraffin mixture with highly crosslinked polymethyl methacrylate (PMMA) shell. According to the manufacturer the product contains: 1,2benzisothiazol-3(2H)-one (22 ppm); 2-methyl-2Hisothiazol-3-one (22 ppm) and a (3:1) mixture of 5chloro-2-methyl-4-isothiazolin-3-one and 2-methyl-4isothiazolin-3-one (13.5 ppm); and a range of particle size of $1-5 \mu \mathrm{m}$. Micronal $^{\circledR}$ DS 5039 X contains 42.0$44.0 \%$ of solids in water. The main peak melting temperature of the product is around $25^{\circ} \mathrm{C}$, the enthalpy of fusion (liquid) $41 \mathrm{~kJ} / \mathrm{kg}$, the latent heat (solid content) $100 \mathrm{~kJ} / \mathrm{kg}$, and the total thermal storage capacity (solid content, integral $10-30^{\circ} \mathrm{C}$ ) $142 \mathrm{~kJ} / \mathrm{kg}$. The advantages of the special microencapsulation process that is used to manufacture Micronal ${ }^{\circledR}$ DS $5039 \mathrm{X}$ are that the product is free of formaldehyde, has high mechanical stability and resistance to high temperatures, and that the polymer capsule is able to resist damage. Mechanical stability should be understood as consistency stability, colour and uniformity of the concentrate structure. A mechanically stable product should maintain the abovementioned features even after prolonged storage (several months). Micronal $^{\circledR}$ DS 5039 X can be employed passively or in combination with an active cooling system. Some other Micronal $^{\circledR}$ products (e.g. Micronal ${ }^{\mathbb{R}}$ DS 5001) has been incorporated in mortar, concrete or plasterboard as a passive system, while it is also used in active systems such as slurries [16].

Seven samples of mPCM slurries by mechanical mixing with the following mass ratios of Micronal ${ }^{\circledR}$ DS $5039 X$ to ERGOLID EKO $^{\circledR}: 30: 70,40: 60,50: 50,60: 40$, 70:30, 80:20 and 90:10, were prepared respectively. The ERGOLID EKO ${ }^{\circledR}$, applied as a base fluid, is a recommended in climatic conditions of Poland commercial product for usage in solar collector installations. The ERGOLID $\mathrm{EKO}^{\circledR}$ contents of $37 \%$ 
pure propylene glycol and $63 \%$ of water with minor fraction of additives. Because Micronal ${ }^{\circledR}$ DS 5039 X contains $42.0-44.0 \%$ of solids in water, the actual mass fraction of microcapsules in the tested suspension was respectively: $12.9,17.2,21.5,25.8,30.1,34.4$ and $38.7 \%$.

\subsection{Experimental set-up}

The viscosity of the slurry was investigated by a Brookfield DV-II+ Pro rotation viscometer (Brookfield Co., Ltd., USA) with a small sample adapter, consisting of a cylindrical sample chamber and spindle coupled with a PolyScience circulating water bath for temperature control (Fig. 1). The small sample adapter provides a defined geometry system for accurate viscosity measurements of small sample volumes at precise shear rates. As the SC4-18 spindle type was used for this viscometer to execute experiments, the sample injected volume was $6.7 \mathrm{ml}$. The small sample adapter's rheologically correct cylindrical geometry provides extremely accurate viscosity measurements and shear rate determinations. The Brookfield viscometer measures viscosity by measuring the force required to rotate a spindle in a fluid at a specified temperature in relation to its shear rate. On the DV+II viscometer type, the viscosity can be read directly or by using the Rheocalc program installed on a computer connected to the viscometer.

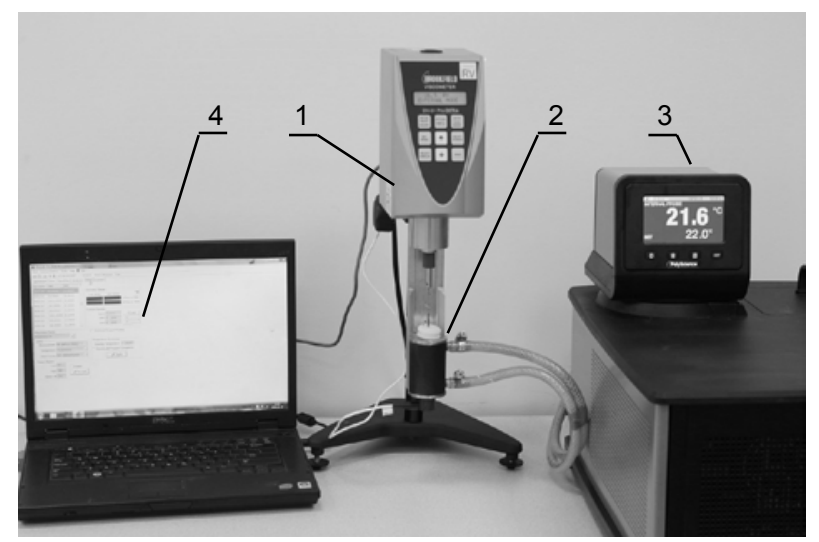

Fig. 1. Experimental set-up: 1 - Brookfield DV-II + Pro viscometer, 2 - small sample adapter, 3 - PolyScience circulating water bath, 4 - computer with the Rheocalc program.

The sample chamber fits into a water jacket so that precise temperature control can be achieved when a circulating water bath is used. The stirring action of the rotating spindle, plus the small sample volume, helps one to keep the temperature gradient across the sample to a minimum. A direct readout of the sample temperature is provided using sample chambers with an embedded RTD sensor connected to the viscometer.

\subsection{Test conditions and procedure}

In this experiment, rotational tests were carried out. These tests entail applying torque (or stress) and measuring the strain, in order to obtain viscosity values. The apparent viscosity-shear rate curves were obtained through a spindle speed from 0.01 to $100 \mathrm{rpm}$ (shear rate 0.0132 to $132.00 \mathrm{~s}^{-1}$ respectively). The measurement of viscosity was carried out when the slurry reached a constant temperature, namely: $10.0 ; 15.0,17.5,20.0$, $22.5,25.0,27.5,30.0,40.0$ and $50.0^{\circ} \mathrm{C}$. At a constant temperature the value of viscosity at eighteen spindle speeds was collected by the Rheocalc program after five minutes of waiting. As a tests for each temperature were repeated three times, mean value of three readings are presented in the figures. Although the Brookfield temperature probe accuracy is $\pm 1^{\circ} \mathrm{C}$, the precision of the bath temperature measurement is $\pm 0.1^{\circ} \mathrm{C}$. As the viscosity accuracy is $\pm 1.0 \%$ of the full scale range (according to spindle type and rotational speed), the allowable error during the experiment is $\pm 3 \mathrm{mPas}$ (for maximum spindle speed).

\section{Results and discussion}

Fig. 2 shows the example relationship between the apparent viscosity and shear rate of Micronal $^{\circledR}$ DS 5039 X slurry.
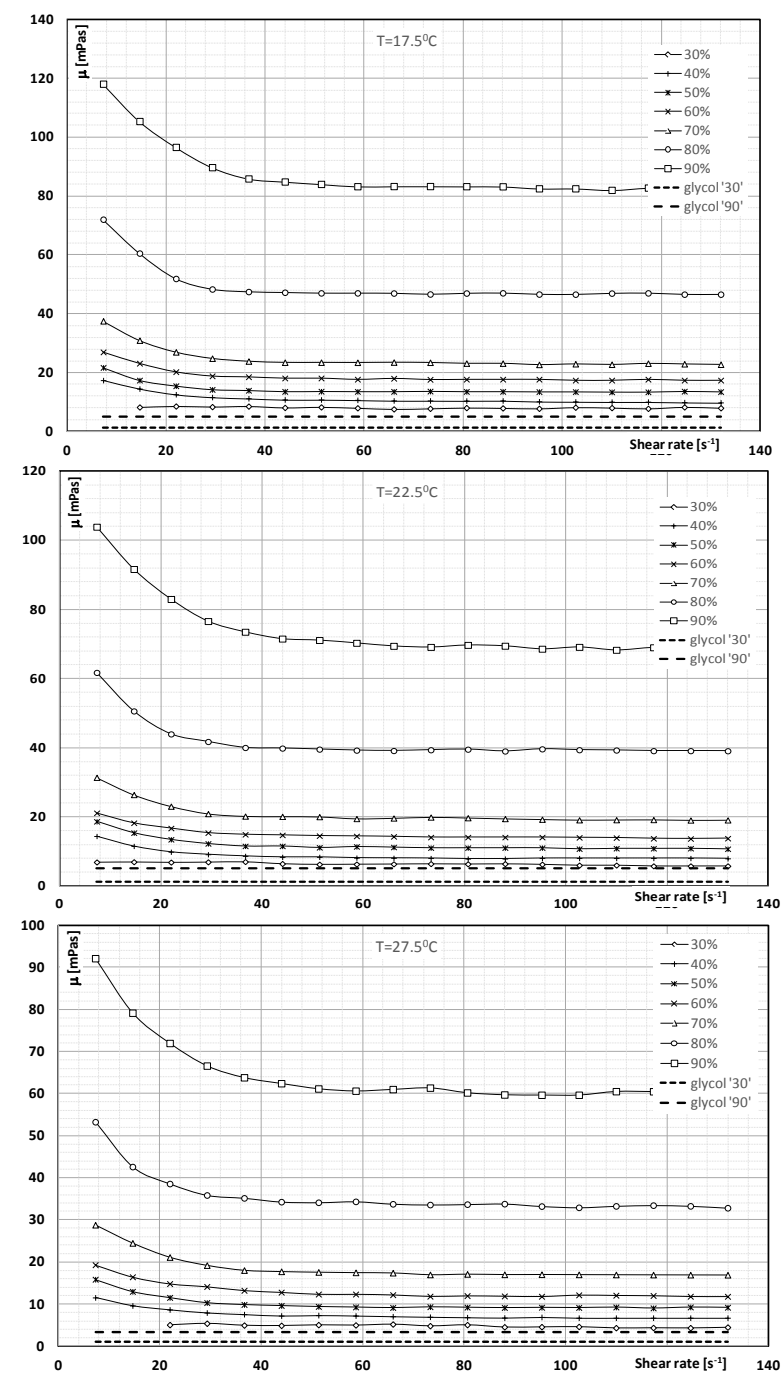

Fig. 2. The apparent viscosities of $\mathrm{mPCM}$ slurries vs. shear rates at different concentrations. 
Each chart represents viscosity results for a different temperature. In each plot, there are several curves corresponding to different mass ratios of Micronal ${ }^{\circledR}$ DS $5039 \mathrm{X}$ to ERGOLID $\mathrm{EKO}^{\circledR}$, namely $30 \%, 40 \%, 50 \%$, $60 \% 70 \%, 80 \%$ and $90 \%$, respectively. Two specific fluids and its viscosities are given as a baseline for the purpose of comparison with obtained results. In Fig. 2 they are displayed with dashed line. First viscosity is the viscosity of a base fluid, which is propylene glycolwater mixture with glycol to water quantity at the same level as in solution of Micronal $^{\circledR}$ DS 5039 X / ERGOLID $\mathrm{EKO}^{\circledR}$ with ratio $30: 70$, it is designated for convenience as glycol ' 30 '. Second viscosity is by analogy, that of base fluid containing the same amount of glycol to water as solution Micronal ${ }^{\circledR}$ DS 5039 X / ERGOLID EKO ${ }^{\circledR}$ with ratio 90:10.

It was observed that, the apparent viscosity of $90 \%$ Micronal $^{\circledR}$ DS 5039 X slurry is approximately several hundred times that of solution of propylene glycol with water at $10^{\circ} \mathrm{C}$ to several dozen times that of solution of propylene glycol with water at $50^{\circ} \mathrm{C}$ (not presented here).

It can be seen from Fig. 2 that, for each temperature of the experiment, the apparent viscosity increases exponentially with the concentration of PCM microcapsules. It is observed that when increasing the shear rate, the apparent viscosity decreases to the Newtonian plateau, where the viscosity seems to be constant. This shear-thinning behaviour has also been found in the majority of the works in this field found in the literature $[5-7,12,13]$.

Fig. 3 presents the results of one's own research and the results of tests according to [3]. This research study [3] was carried out using another BASF Micronal ${ }^{\circledR}$ DS $5008 \mathrm{X}$ product. The viscosity of the $25 \%$ aqueous suspension was measured at $15^{\circ} \mathrm{C}$. According to the comparison of test results, Micronal ${ }^{\circledR}$ DS 5008 X's apparent viscosity characteristics are faster, while the viscosity of this suspension is comparable to the $70 \%$ viscosity of the Micronal ${ }^{\circledR}$ DS 5039 X suspension.

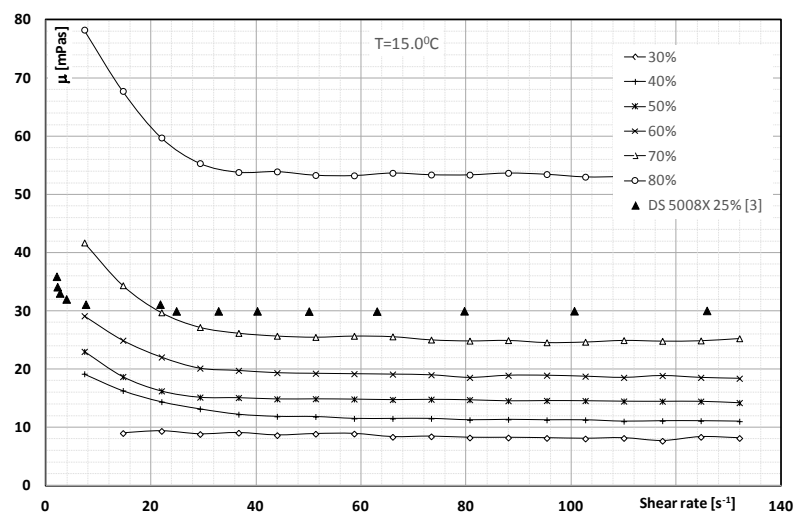

Fig. 3. View of apparent viscosity characteristics for mPCM slurries at different concentrations.

The results of one's own research indicate that shearthinning behaviour is valid for every case except for the slurry with $30 \%$ concentration. In this particular case, mPCM slurry may be considered as a Newtonian fluid in the whole range of shear rate. This fact is confirmed by a detailed visual inspection of the characteristics obtained for other temperature values (not presented here).

Another regularity can be observed. With an increasing shear rate, apparent viscosity drops rapidly at first, then becomes lower until the value of apparent viscosity does not change much. The slurries under examination in the experiment were in the range of pseudoplastic fluids. This shear thinning behavior can be explained through the spatial layout of the microcapsules in suspension. When a slurry is stable and at rest, the particles are dispersed randomly in the continuous phase. When the slurry begins to be sheared, there is no cooperative motion between the microcapsules. The capsules move in an unorganized manner, not necessarily in accordance with the bulk flow direction and therefore the apparent viscosity is high. When the slurry is sheared at high shear rates, the microcapsules start to move in layers that form in parallel to the main flow. Due to this, the average distance between microcapsules decreases in the direction of flow and increases in the direction perpendicular to it. This change of the spatial layout makes the motion much easier, which can be observed as a decrease in viscosity [2].

It may be seen from Figs. 2 and 3 that after exceeding a certain value of shear rate, the decrease in apparent viscosity becomes less prominent and apparent viscosity drops in a linear fashion or becomes constant. The higher the slurry temperature, the lower this threshold shear rate. When the sample temperature was $50^{\circ} \mathrm{C}$, a linear characteristic is displayed after exceeding a shear rate of $30 \div 40 \mathrm{~s}^{-1}$, and for a sample at $20^{\circ} \mathrm{C}$, this threshold shear rate is between $40 \div 60 \mathrm{~s}^{-1}$. This shear thinning behaviour has been explained by Delgado et al. [2] in relation to microcapsules. It is stated that when microcapsules are randomly dispersed in a base fluid in a stagnation condition, the apparent viscosity is high. When approaching higher shear rates, the particles form layers with a low distance between particles in the flow direction and high distance between various layers. This effectively lowers friction between layers and, therefore, apparent viscosity. The phenomenon observed in Figs. 2 and 3 shows that with the higher temperature of sample, the transition to the Newtonian plateau is quicker as the formation of the abovementioned layers occurs much earlier. This may be caused by lower viscosity of the carrier fluid itself at higher temperatures.

\section{Apparent viscosity of slurry - predictive model}

There are many formulas that serve to describe the viscosity of non-Newtonian fluids. Some of them, in their original or modified form, take into account the influence of concentration (equations based on Einstein's Brownian motion theory $[17,18]$ ), the influence of temperature (equations originating from Arrhenius's law [19-23]), or the impact of the shear rate (as the Ostwald equation [24-26] also known as the Power-law model). It is known that all the above-mentioned factors highly influence viscosity. 
In present work, the viscosity of slurry created from Micronal $^{\circledR}$ DS $5039 \mathrm{X}$ product and an aqueous solution of propylene glycol was calculated according to a modified Vogel-Tamman-Fulcher equation:

$$
\mu=\exp \left(B_{1}+\frac{B_{2}}{T}+\frac{B_{3}}{T^{2}}\right),
$$

where $\mu$ is the viscosity of fluid, $T[\mathrm{~K}]$ its temperature and $B_{\mathrm{i}=1,2,3}$ dimensionless fitting coefficients. On the one hand, a second-order term was added [20] to obtain a better fit between the experimental and calculated viscosity data. On the other hand, several researchers $[21,22,27,28]$ have used a fitting coefficients $B_{i}$ as a function of the components concentration $\phi$ :

$$
B_{i}=b_{i 1}+b_{i 2} \cdot \emptyset+b_{i 3} \cdot \emptyset^{2},
$$

where $b_{i l}, b_{i 2}, \quad b_{i 3}$ are empirical constants (fitting parameters).

The values of dimensionless parameters for the model of viscosity were acquired by least-squares regression method. The regressed values are summarized as below:

$$
\left\{\begin{array}{c}
B_{1}=0.47-1,97 \cdot \emptyset+22.5 \cdot \emptyset^{2} \\
B_{2}=38.9-13.62 \cdot \emptyset-5.48 \cdot \emptyset^{2} \\
B_{3}=-125-640 \cdot \emptyset+1500 \cdot \emptyset^{2}
\end{array}\right.
$$

In addition to the obtained values of $b_{i j}$ coefficients, the value of mean absolute error MAE was calculated. The MAE describes average model performance error

$$
M A E \%=\frac{100}{N} \cdot \sum_{1}^{N}\left(\frac{\left|\mu_{t h}-\mu_{\exp }\right|}{\mu_{\exp }}\right) ;
$$

where $N$ - sample count. The mean absolute error for investigated cases is MAE $=10.76 \%$.

Fig. 4 presents a comparison of the calculation results of dynamic viscosity according to the dependences (1) and (3) with the results of experimental research. An analysis of over 1250 cases shows that $85.1 \%$ of the results were calculated with a deviation of less than \pm $20 \%$.

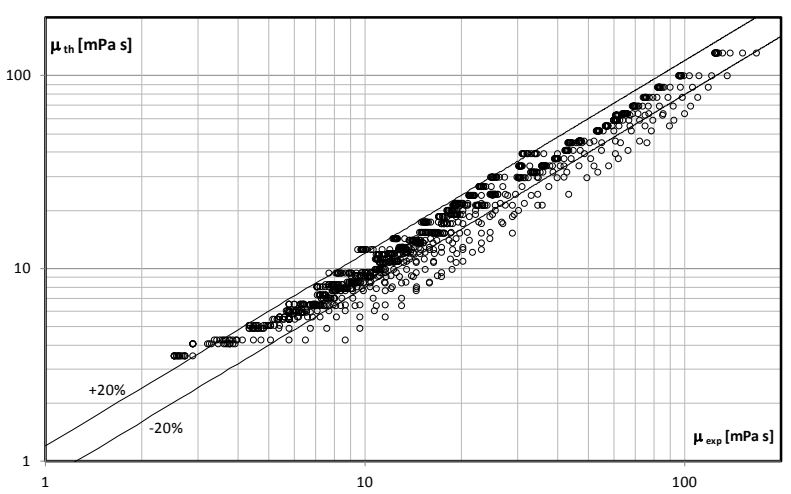

Fig. 4. The comparison of the calculation results of viscosity with the results of experimental research.

\section{Conclusions}

Experimental investigations were carried out to investigate the microencapsulated phase change slurries (Micronal $^{\circledR}$ DS $5039 \mathrm{X}$ - aqueous solution of propylene glycol) in terms of their rheological properties. The Brookfield DV-II+ Pro rotation viscometer (Brookfield Co., Ltd., USA) with the small sample adapter, consisting of a cylindrical sample chamber and spindle coupled with circulating water bath was used for measuring viscosity equipment. Experiments were conducted on seven types of mPCM slurry with the following mass ratios of Micronal $^{\circledR}$ DS $5039 \mathrm{X}$ to aqueous solution of propylene glycol: 30:70, 40:60, 50:50, 60:40, 70:30, 80:20 and 90:10. The apparent viscosity-shear rate curves were obtained through a shear rate from $0.0132 \mathrm{~s}^{-1}$ up to $132.00 \mathrm{~s}^{-1}$. The following conclusions of these experimental investigations may be drawn:

1) The apparent viscosity of Micronal ${ }^{\circledR}$ DS $5039 \mathrm{X}-$ aqueous solution of propylene glycol slurries increased with a rising $\mathrm{mPCM}$ concentration.

2) With an increasing shear rate, the apparent viscosity of slurry decreases to the Newtonian plateau, where the viscosity seems to be constant. The higher the concentration, the lower the shear rate value becomes a threshold for linear behaviour. The higher the temperature of the slurry, the lower the shear rate value, after which the apparent viscosity characteristic becomes linear or constant.

3) Only the $30 \%$ Micronal $^{\circledR}$ DS 5039 X slurry (12.9 $\mathrm{wt} \%$ solid of $\mathrm{mPCM}$ in liquid) can be considered as a Newtonian fluid within the whole test region (shear rate 0.0132 to $132.00 \mathrm{~s}^{-1}$ ).

4) The measured values of viscosity were used to estimate the optimal values of fitting coefficients of modified Vogel-Tamman-Fulcher equation.

5) It was found that $85.1 \%$ of the results were correctly calculated using the proposed values of the modified Vogel-Tamman-Fulcher equation coefficients.

The authors are thankful to the BASF, Germany, for supplying samples of Micronal ${ }^{\circledR}$ DS 5039 X.

We would also like to thank Dr. Paul McNamara for conducting the linguistic verification of this article.

\section{References}

1. R. Yang, H. Xu, Y. Zhang, Sol. Energy Mater. Sol. Cells. 80, 405-416 (2003)

2. M. Delgado, A. Lázaro, C. Peñalosa, B. Zalba, Appl. Therm. Eng. 63, 11-22 (2014)

3. G.H. Zhang, C.Y. Zhao, Renew. Energy. 36, 2959 2966 (2011)

4. Y. Allouche, S. Varga, C. Bouden, A.C. Oliveira, Energy Convers. Manag. 94, 275-285 (2015).

5. M. Kong, J.L. Alvarado, W. Terrell, C. Thies, Int. J. 
Heat Mass Transf. 101, 901-914 (2016)

6. L. Wang, J. Zhang, Y. Wang, X. Lin, N. Xie, H. Chen, Appl. Therm. Eng. 99, 583-590 (2016)

7. W. Fu, X. Liang, H. Xie, S. Wang, X. Gao, Z. Zhang, Y. Fang, Energy Build. 136, 26-32 (2017)

8. L. Chen, T. Wang, Y. Zhao, X.R. Zhang, Energy Convers. Manag. 79, 317-333 (2014)

9. M. Jurkowska, I. Szczygieł, Appl. Therm. Eng. 98, 365-373 (2016)

10. Y. Yamagishi, H. Takeuchi, A. Pyatenko, N. Kayukawa, Am. Inst. Chem. Eng. 45, 696-707 (1999)

11. M. Delgado, A. Lázaro, J. Mazo, B. Zalba, Renew. Sustain. Energy Rev. 16, 253-273 (2012)

12. C. Liu, Z. Ma, J. Wang, Y. Li, Z. Rao, Int. J. Heat Mass Transf. 115, 737-742 (2017)

13. L.Y. Li, D. Zou, X.F. Ma, X.S. Liu, Z.G. Hu, J.R. Guo, Y.Y. Zhu, Energy Convers. Manag. 135, 170177 (2017)

14. Z. Qiu, X. Ma, P. Li, X. Zhao, A. Wright, Renew. Sustain. Energy Rev. 77, 246-262 (2017)

15. L. Liu, G. Alva, X. Huang, G. Fang, Renew. Sustain. Energy Rev. 66, 399-414 (2016)

16. J. Giro-Paloma, G. Oncins, C. Barreneche, M. Martínez, A.I. Fernández, L.F. Cabeza, Appl. Energy. 109, 441-448 (2013)

17. P. Zhang, Z.W. Ma, Z.Y. Bai, J. Ye, Energy. 106, 63-72 (2016)
18. S. Mossaz, J.A. Gruss, S. Ferrouillat, J. Skrzypski, D. Getto, O. Poncelet, P. Berne, Appl. Therm. Eng. 81, 388-398 (2015)

19. D. V. Boger, An Introduction to Rheology, 1989.

20. D.I. Sagdeev, M.G. Fomina, G.K. Mukhamedzyanov, I.M. Abdulagatov, J. Chem. Thermodyn. 43, 1824-1843 (2011)

21. L.A. Tirona, R.B. Leron, A.N. Soriano, M.H. Li, J. Chem. Thermodyn. 77, 116-122 (2014)

22. C.P. Liao, R.B. Leron, M.H. Li, Fluid Phase Equilib. 363, 180-188 (2014)

23. D.I. Sagdeev, M.G. Fomina, I.M. Abdulagatov, Fluid Phase Equilib. 450, 99-111 (2017)

24. A.K. Pandey, M.S. Hossain, V. V. Tyagi, N. Abd Rahim, J.A.L. Selvaraj, A. Sari, Renew. Sustain. Energy Rev. 82, 281-323 (2018)

25. L. Huang, M. Petermann, Int. J. Heat Mass Transf. 83, 479-486 (2015)

26. B. Muñoz-Sánchez, J. Nieto-Maestre, E. Veca, R. Liberatore, S. Sau, H. Navarro, Y. Ding, N. Navarrete, J.E. Juliá, Á.G. Fernández, A. GarcíaRomero, Sol. Energy Mater. Sol. Cells. 176, 357373 (2018)

27. S. Garg, G. Murshid, F.S. Mjalli, A. Ali, W. Ahmad, Chem. Eng. Res. Des. 118, 121-130 (2017)

28. G. Murshid, H. Ghaedi, M. Ayoub, S. Garg, W. Ahmad, J. Mol. Liq. 250, 162-170 (2018) 